\title{
Optimal distribution of power under stress on power grid in real-time by reactive compensation-management and development in balance
}

\author{
Tadjeddine Ali A. ${ }^{1}$, Arbaoui I. $^{2}$, Hamiani H. ${ }^{3}$, Chaker $\mathbf{A}^{4}$ \\ ${ }^{1,4}$ SCAMRE Laboratory, National Polytechnic School of Oran, Algeria. \\ ${ }^{2}$ LESEM Laboratory, University Oran1, Algeria. \\ ${ }^{3}$ LAAS Laboratory, National Polytechnic School of Oran, Algeria
}

\begin{tabular}{l} 
Article Info \\
\hline Article history: \\
Received Jul 17, 2019 \\
Revised Nov 9, 2019 \\
Accepted Feb 7, 2020 \\
\hline Keywords: \\
Decentralized Production \\
Dispatching \\
Power Integration \\
PV \\
Real Time
\end{tabular}

Real Time

\begin{abstract}
The industrial development, lifestyle and modernization of the management sectors in Algeria have led to an increase in demand for electricity power in recent years and an increase in demand for the energy sector. This high demand for power has led to problems with voltage drops, particularly as regards the quality of this voltage during periods peak load. Thanks to research on the development of the electricity transmission system in the South-West region of Algeria and based on the theoretical results. We have obtained an optimal solution for the location of the regulation systems for voltage and the frequency in the substations that exhibit strong violations and periodic static destabilization, in particular, the stations at the end of the $220 \mathrm{Kv}$ transmission lines. The techniques of modeling and controlling the voltage per frequency $(\mathrm{Hz} / \mathrm{V})$ as well as the critical analysis variants have been studied and confirmed using advanced real-time numerical simulation.
\end{abstract}

This is an open access article under the CC BY-SA license.

Corresponding Author:

Tadjeddine Ali A.,

SCAMRE Laboratory, Department of Electrical Engineering,

National Polytechnic School of Oran - Maurice Audin, Algeria.

Email: atadj1@gmail.com

\section{INTRODUCTION}

The growing demand for energy and the development of decentralized generation systems have led to great progress in the field of quality control of voltage and active and reactive power. Nevertheless, the regulation of the quality of energy and the appearance of new compensation devices have allowed a better control of the electrical energy. The more the network grows the more complex it becomes, difficult to control and its margin of stability decreases $[1,2]$. For this, the structure of the southern network requires the operator to find an optimal solution to the problems relating to compensation in order to maintain the stability of the electrical system and continuity of service. Interest in the installation of electronic power devices in substations has increased significantly in recent years. In fact, static converters can meet the quality requirements imposed by the electric power supplier and ensure the proper functioning of the substations [3]. The control aspects of reactive power and voltage stability are effective for the reliability of power grids. Voltage instability usually occurs because of a reactive power deficit. Therefore, the control of the reactive power and the voltage is one of the major challenges for the dispatcher of the electrical networks $[4,5]$. Electrical grid analysis and planning has not only helped to control power systems, but also to develop these systems, including lines, transformers, and reactive compensation [6]. Consequently, the optimal supervision of integration of renewable energy resources (photovoltaic and wind) and reactive 
power control devices in electrical networks call for real-time status information to synchronize between all the sources in the network, so improve energy efficiency and voltage profiles of substations under different operating conditions $[7,8]$. The good quality of electrical powers and the continuity of services play the crucial role in the optimal management of the electric network on the one hand, and on the other hand, the compensation of the reactive power transmitted is the means that ensures the stability of the voltage and increasing the flow of active power [9]. The shunt compensation can be installed near the load, in a distribution station, along the distribution outlet or in a transport station. Each application has different objectives. Reactive shunt compensation can be inductive or capacitive. At the load level, at the distribution station and along the start of the distribution, compensation is generally capacitive $[10,12]$.

\section{LITERATURE REVIEW}

\subsection{Reactive energy compensation}

The transmission of reactive power by distribution lines and transformers has many drawbacks with regard to the construction and operation of the electrical system. Active losses are increased and a higher cross-section of the lines is sometimes required. Reactive losses (transformers) are also increased [13, 14]. The reactive power has always been difficult to achieve a balance between a minimum amount of reactive power flow $\mathrm{Q}$ and a sufficient amount of reactive power flow to maintain a proper voltage profile of the network (maximizing active power flow capacity P) $[15,16]$. The voltage setting on an electrical network is strongly related to reactive power transits [17]. The first step to maintain the voltage at a correct level is to minimize these transits, forcing customers connected to the network to limit their reactive power consumption (the loads are in fact mainly inductive) [20]. This reactive power compensation is usually done through capacity banks connected to the bus bar of the arrival of the station. An alternator can also perform it, at least partially. The power factor $(\mathrm{PF})$ is equal to the ratio of the active power $\mathrm{P}$ MW to the apparent power S MVA [11]. The power factor or almost $\operatorname{Cos}(\varphi)$ and $\tan (\varphi)$ are linked by the following relation:

$$
\operatorname{Cos} \varphi=\frac{1}{\sqrt{1+(\operatorname{tg} \varphi)^{2}}}
$$

with: $\operatorname{Cos}(\varphi)=\frac{P}{S} \tan (\varphi)=\frac{Q}{p}$

The reactive power plant $\mathrm{Q}$, and apparent power $\mathrm{S}$, a bank of capacitors Qc power is installed.

- $\quad$ The reactive power goes from $\mathrm{Q}$ to $\mathrm{Q}$ ':

- The apparent power goes from $\mathrm{S}$ to $\mathrm{S}$ '.

- $\quad$ The apparent power after compensation $S$ 'is therefore decreased.

- $\quad$ The capacity of compensation by the capacitors is calculated by:

$$
\begin{aligned}
& Q C=3 . U^{2} \cdot C . \omega \quad \ldots a \\
& C=\frac{P_{\max }\left(\tan \left(\varphi^{\prime}\right)-\tan (\varphi)\right)}{3 \cdot U^{2} \cdot \omega} \ldots b
\end{aligned}
$$

with: $Q^{\prime}=Q-Q c$

Figure 1 shows the diagram of the compensation of the reactive energy by the compensation capacitors.

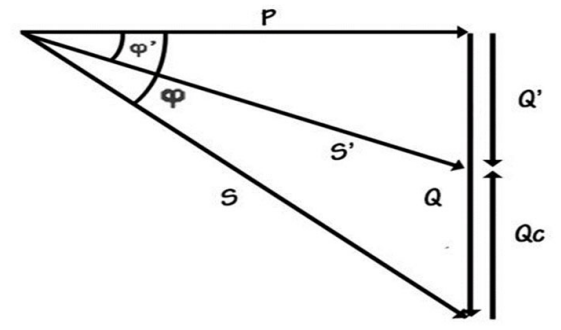

Figure.1 Fresnel representation of active, reactive and apparent power vectors

The maximum transferable power $\boldsymbol{P}_{\max }$ given by [21]:

Int J Pow Elec \& Dri Syst, Vol. 11, No. 2, June 2020 : $685-691$ 
$P_{\max }=\frac{u \cdot U \cdot A \cdot \kappa}{100 \% \cdot l}$

So, The relative loss of transmissible power $\Delta p$ is [17] :

$$
\Delta p=\frac{U}{\left(\cos \left(\varphi_{H V}\right)\right)^{2}}
$$

\subsection{Voltage drop in a ps load}

When the currents are very high, the voltage drops in the Ohmic resistances of the primary and secondary transformer windings and in the leakage, inductors must be taken into account [22, 25]. The magnetizing current and the iron losses remain linked to the flux. In practice, the voltage drop in the primary resistances and reactance is weak in front of the voltage by using the Kapp equation, we will have [24]:

$$
\frac{n_{2}}{n_{1}} \cdot U_{1}=U_{2}+\left(R_{s}+j w l_{s}\right) I_{2}
$$

with:

U1 and U2: Primary and secondary voltages,

Rs and 1s: Resistance of the windings and the inductance of leaks brought back to secondary.

$\mathrm{n} 1$ and $\mathrm{n} 2$ : Number of primary and secondary turns.

In reality, Rs I2, and Is are weak in front of U2 and we can often use a simplified relation, we can build the in addition, the voltage drops in the system are increased, hence the need to choose a higher regulation range of tap changers for autotransformers in normal situation $(\mathrm{N})$ or another method of which the most recognized is the disconnect of charge in critical situation $(\mathrm{N}-1)$ called the electrical load shedding [26-28]. The voltage drop of a transmission line for the three-phase AC system is given by the following equation [29]:

$$
U=\frac{100 \% \cdot P_{\max } \cdot l}{\kappa \cdot A \cdot U 2}=\frac{100 \% \cdot \sqrt{3} \cdot I_{l} \cdot \cos \varphi \cdot l}{U \cdot A \cdot \kappa}
$$

with: $\mathrm{A}=$ cross-section, $\mathrm{I}=$ line length, $\mathrm{Il}=$ line current, $\mathrm{P}=$ active power to be transmitted, $\kappa=$ electrical conductivity, $\mathrm{U}=$ phase-to-phase voltage, $\mathrm{u}=$ relative voltage $(\%), \cos \phi 1=$ power factor

Fresnel vectors associated with the voltages, the equation of the voltage drop: \The voltage drop is a difference of the RMS values of the unloaded and unloaded secondary voltage for the same primary voltage U1.

$$
\Delta U_{2}=\operatorname{Abs}\left(U_{2}-U_{20}\right)
$$

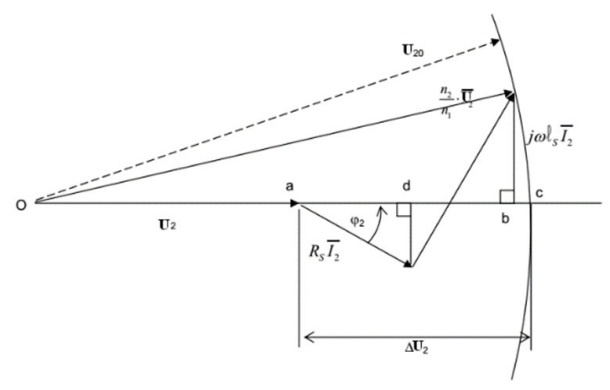

Figure 2. Fresnel representation of voltage vectors [30].

Using Figure 2 the projection on the axis ab, the development of the equation gives [26]:

$\Delta U_{2}=\left(R_{s} \cos \left(\varphi_{2}\right)+X_{s} \sin \left(\varphi_{2}\right)\right) I_{2}$

The voltage drop is proportional to the current output and the nature of the load.

Optimal distribution of power under stress on power grid in real-time by... (Tadjeddine Ali A) 
By adjusting the reactive power $Q_{C . L V}$ in low voltage bus delivered to the electrical network, a TSC makes it possible to adjust the voltage $U_{i}$ of the network according to the formula [28]:

$$
\frac{\Delta U_{i}}{U_{i}}=\frac{Q_{C . L V}}{S_{c c_{i}}}=\frac{P_{L V}\left(\tan \left(\varphi_{B u s 1}\right)-\tan \left(\varphi_{B u s 2}\right)\right)}{\sqrt{P_{c c_{i}^{2}}+Q_{c c_{i}^{2}}}}
$$

with:

$\frac{\Delta U}{U}$, Represents the relative voltage variation,

$S_{c c}$, The short-circuit power of the network.

\section{RESULTS}

\subsection{System description}

The studied system is composed as indicated in Table 1 below:

Table 1. Description of the electrical system

\begin{tabular}{lll}
\hline \multirow{2}{*}{ Generator } & Central TG/CC & \\
\hline \multirow{2}{*}{ buses } & Load buses & Generator buses \\
Transformers & 17 & 02 \\
Lines & 10 & \\
\hline
\end{tabular}

\subsection{Voltage control and transit limits}

Table 2 below illustrates the voltage and transit limits;

Table 2. Limit of node voltages and transits under normal conditions

\begin{tabular}{|c|c|c|}
\hline Voltage & Lower limit & upper limit \\
\hline $220 \mathrm{KV}$ & $0.93 \mathrm{pu}$ & $1.09 \mathrm{pu}$ \\
\hline $60 \mathrm{KV}$ & $0.93 \mathrm{pu}$ & $1.09 \mathrm{pu}$ \\
\hline Transits & & \\
\hline Line & $80 \%$ & \\
\hline Transformer & $80 \%$ & \\
\hline
\end{tabular}

Figure 3 shows the implementation of the study model in the RT simulator.

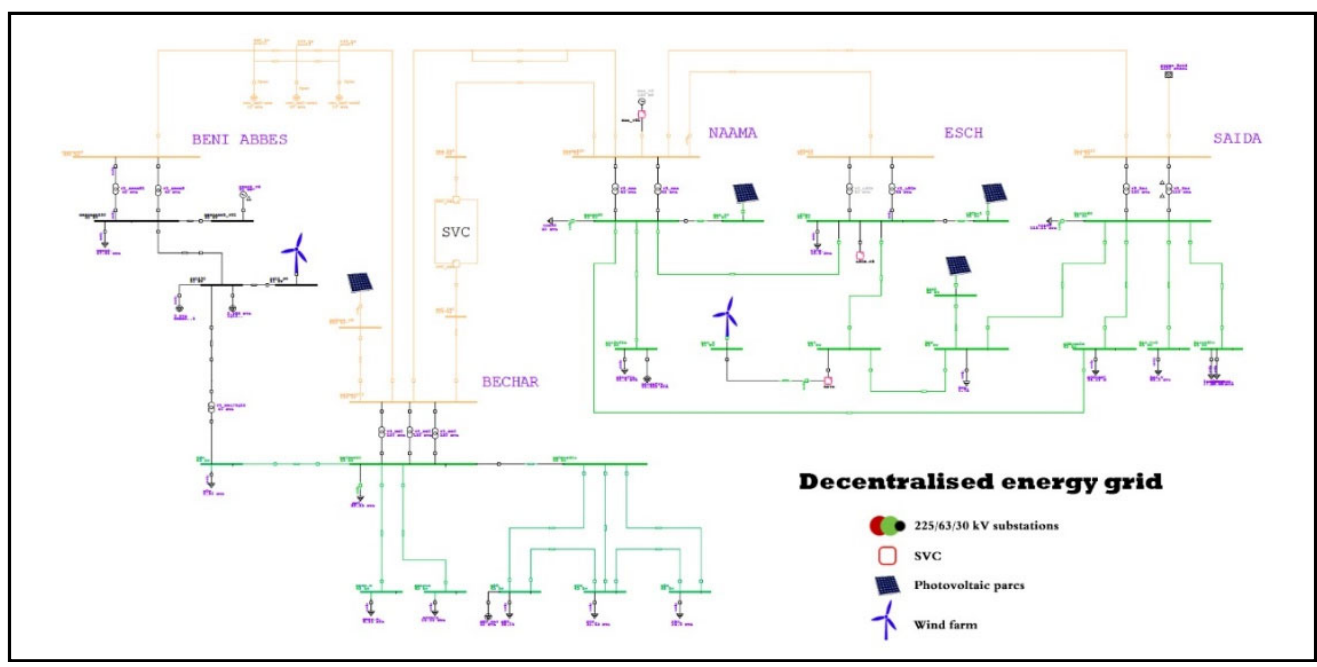

Figure 3. The model to study under the RT simulator 


\subsection{Simulations results}

The results were calculated by the accelerated Gauss-Seidel method with the acceleration factor of 1.45 and a precision of $10^{-6}$.

Case 01: calculation without compensation

The results obtained for 220/60 kV voltages without compensation are shown in Figure 4.

Profil de tension en pu sans compensation

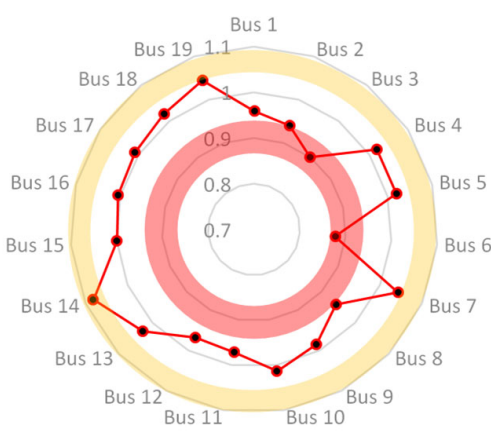

Figure 4. Variation of load voltages according to the marginal and critical nodes without compensation (PF)

Case 02: Calculation with optimal compensation

The Figures 5 shows the change in the voltage according to the known powers:

Profil de tension en pu avec compensation

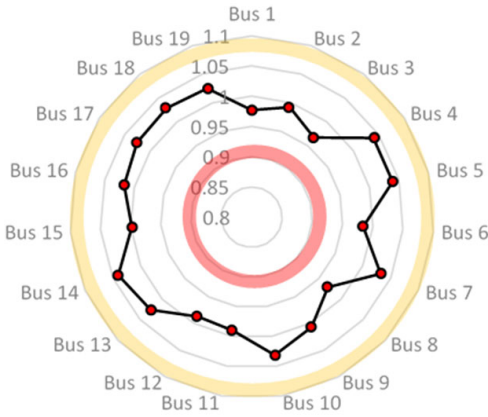

Figure 5. Variation of the load voltages according to the marginal and critical nodes with optimal compensation (OPF)

\section{DISCUSSIONS}

From the Figure 4, it is noted that there are violations in voltage in 08 different stations of levels $220 / 60 \mathrm{kV}$ respectively. We have two types of violations, either critical or marginal in the normal situation $\mathrm{N}$ at the peak of a summer day in July 2018. The radial type network, and subsequently the voltage drops in the remote stations due to the large loads consumed is very logical. This problem appears clearly in the nodes mentioned in figure 4, and in particular in the following critical nodes: Bus 2, Bus 3, Bus 6, and Bus 14 they are located in the end of the line. After several alternative optimal installation of the compensation means in the network nodes, the optimal stations located for the compensation are as follows in Bus2, Bus 9, and Bus 12. The optimal solution proposed is to install a capacity of eight Mvar on the two nodes: bus two and nine and another capacity of 10 Mvar on the node: Bus 12 . The optimal compensation of reactive in these nodes will strengthen the margin of stability for power transmission in the southern region of Algeria.

Optimal distribution of power under stress on power grid in real-time by... (Tadjeddine Ali A) 


\subsection{PERTES ACTIVES DU SYSTÈME} compensation:

The Figure 6 shows the results of active losses during peak hours without and with optimal

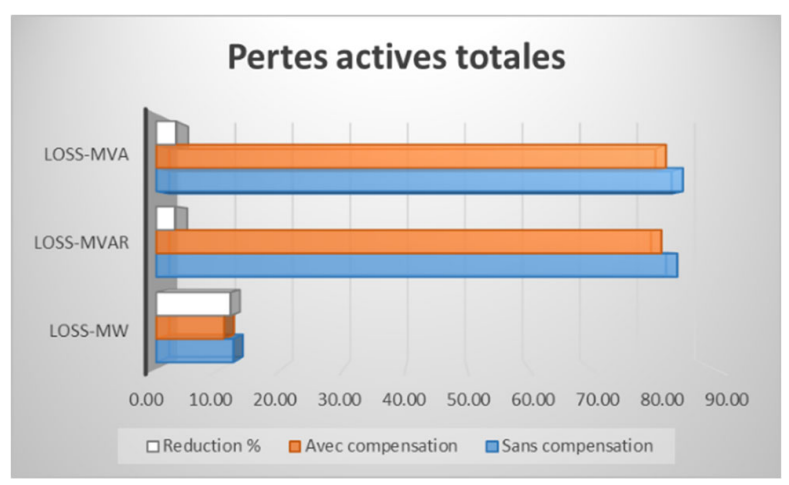

Figure 6. Total active losses

In Table 7 presents the results of the active losses in the different cases with the rate of reduction.

Table 7: Reduction Total active losses

\begin{tabular}{llll}
\hline & Loss-MW & Loss-Mvar & Loss-MVA \\
\hline Without compensation (PF) & 12.40 & 83.69 & 84.60 \\
With OPF & 10.92 & 81.15 & 81.88 \\
Reduction \% & 11.91 & 3.04 & 3.22 \\
\hline
\end{tabular}

The results obtained show that after compensation of the reactive energy, the active losses of the system are reduced. The loss reduction rate using conventional compensation means in substations with voltage violations is estimated at $11.91 \%$ compared to the first case, which increases the capacity of transit power.

\section{CONCLUSIONS}

We have studied the problem of optimal control of voltage and reactive power in radial type network of the SAIDA-Becher area located in south-west of Algeria. The choice of location of the compensation point is of crucial importance for maintaining the voltage within the permissible limits and resolving the voltage drops in the $60 \mathrm{kV}$ substations. This scenario planning for the South-West Algerian power grid is very useful, it will make it possible to predetermine the next state of the network for a given production plan as well as for a demand in fixed power, there exists a priori an infinity of plans of production possible. For this, the optimal distribution of the power appeared to optimize the production on the various power stations and to maximize the transit of power while continuing to satisfy this demand in an economical and reliable way. The advantage of using digital environments has made it possible to improve the quality of the study and to save a lot of time, in particular in the technical problems that it contains the algorithms and its convergence problems.

\section{REFERENCES}

[1] K. Tong, Y. Jiangang, "A Hybrid Approach for Power System Security Enhancement via Optimal Installation of Flexible AC Transmission System (FACTS) Devices”, Energies, 10, 1305, 2017.

[2] T. Ayumu, Y. Hiroaki, and other, "New Hybrid Static VAR Compensator with Series Active Filter", Energies 10, 1617, 2017.

[3] T. Rikanth, S. Selvi, P. Pushya, "Optimal Placement of Static VAR Compensator (SVC) in Power System along with Wind Power Generation”, IEEE, Automatic Control ICEICE2017, 1-6, 2017.

[4] D. William, "Elements of power system analysis", Edition Dunod, paris, 2001.

Int J Pow Elec \& Dri Syst, Vol. 11, No. 2, June 2020 : 685 - 691 
[5] M.G. Molina, "Modelling and Control of Grid-connected Solar Photovoltaic Systems", Chap3, Renewable Energy Utilization and System Integration, pp. 53-83. 2016.

[6] A.U. Lawan, S. Babani, and others, "Power compensation for vector-based current control of a modular multilevel converter (MMC) based STATCOM" International Journal of Power Electronics and Drive System (IJPEDS), vol. 10, no. 4, pp. 1781-1796, 2019.

[7] L.L. Grigsby, "Electric Power Generation, Transmission, and Distribution - Third edition," book, CRC Press edition, Electric Power Generation, pp. 2.1-2.9, 2012.

[8] A.M. Elsherbiny, A.S. Nada, Mohammed Kamal, "Smooth transition from grid to standalone solar diesel mode hybrid generation system with a battery", International Journal of Power Electronics and Drive System (IJPEDS), vol. 10, no. 4, pp. 2065-2075, 2019.

[9] W. Zhang, W. Liu, and others, "Distributed multiple agent system based online optimal reactive power control for smart grids," IEEE Trans. Smart Grid, vol.5, no. 5, pp.2421-2431, 2014.

[10] C. R. Bayliss, B. J. Hardy, "Transmission and Distribution Electrical Engineering”, Book, fourth edition, Newnes edition, Chap.28 Fundamentals, pp. 1124-1131, 2012.

[11] A. Abdulkarim, S.M. Abdelkader, and others, "Effect of weather and the hybrid energy storage on the availability of standalone microgrid" International Journal of Renewable Energy Research (IJRER), Vol. 6, no. 1, pp. 189-198, 2016.

[12] D.P. Rommel, D. Di Maio, T. Tinga, "Calculating wind turbine component loads for improved life prediction", Elsevier Ltd, Renewable Energy 146, 2020, 223-241.

[13] I. Vechiu, "Modélisation, Commande et Intégration de la Production Décentralisée dans les $\mu$ réseaux", dissertation, Grenoble INP, chap.01\&04, 2013.

[14] M. Ahmed, M. EL-Shimy, and others, "Sizing of reactive power compensators for onshore and offshore grid connected wind farms", Industry Academia Collaboration (IAC) Conference, Energy and sustainable development Track, Apr. 6-8, 2015.

[15] N.M. Salgado Herrera, A. Medina-Rios, R. Tapia-Sánchez and others, "Reactive Power Compensation in Distributed Networks with Wind Turbine Integration using Resonant Corrector”, IEEE, 978-1-5090-4281-4/17, 2017.

[16] V. C. Sekhar, K. Kant, B. Singh, "DSTATCOM supported induction generator for improving power quality", IET Renewable Power Generation, vol. 10, no. 4, pp. 495-503, 42016.

[17] M. EL-Shimy, "Reactive power management and control of distant large-scale grid connected offshore wind power farms", International Journal of Sustainable Energy, iFirst, 2012, 1-17.

[18] M. Naser, A. Aghbolaghi, and others, "Power Systems Reactive Power Control in AC Power Systems Fundamentals and Current Issues", Edition springer, 2017.

[19] Ali.A. Tadjeddine, A. Chaker, M. Khiat, L. Abdelmalek, N. Khalfalah, "A contribution to the control of voltage and power of the interconnection between two decentralized electrical grids with an optimal localization of the SVC devices in real-time", International Journal of Power Electronics and Drive System (IJPEDS), Vol. 10, no. 1, pp. 170 177, 2019.

[20] Aya M. Elsherbiny, Adel S. Nada, Mohammed Kamal, "Smooth transition from grid to standalone solar diesel mode hybrid generation system with a battery", International Journal of Power Electronics and Drive System (IJPEDS), Vol. 10, no. 4, pp. 2065-2075, 2019.

[21] H. Wolfgang, S. Jurgen, J. Wolfgang, "Reactive Power Compensation - A Practical Guide", Wiley edition, chap.3 Effect of Reactive Power, pp.22-27, 2012.

[22] T. Srikanth, S. C. Selvi, V. N. Pushya, "Optimal placement of static VAR compensator (SVC) in power system along with wind power generation", IEEE International Conference on Electrical, Instrumentation and Communication Engineering (ICEICE), Karur, pp. 1-6, 2017.

[23] Deshpande Chinmay V., Deshpande Chaitanya V., "Optimum design of dynamic voltage restorer for voltage sag mitigation in distribution network", International Journal of Power Electronics and Drive System (IJPEDS), Vol. 10, no. 3, pp. 1364-1372, 2019.

[24] Shaimaa Shukri A. Alhalim, Lubna A. Alnabi, "Enhancement transient stability of wind power system of DoublyFed induction generator using STATCOM and PI controller", International Journal of Power Electronics and Drive System (IJPEDS), Vol. 10, no. 4, pp. 1977-1985, 2019.

[25] J. Morin, "Coordination des moyens de réglage de la tension à l'interface réseaux de transport et de distribution, évolution du réglage temps réel de la tension dans les réseaux de distribution", École doctorale: Science des Métiers de l'ingénieur, 2016.

[26] J.H. Gridley, "Principles of Electrical Transmission Lines in Power and Communication", Pergamon Press Ltd. First Edition.

[27] C.J. Wong, M.D. Mille, "Guidelines for Electrical Transmission Line Structural Loading”, American Society of Civil Engineers, Third Edition, 2010.

[28] S. X. Chen, Y. S. Foo. Eddy, and other, "A Centralized Reactive Power Compensation System for LV Distribution Networks”, IEEE Transactions On Power Systems, 2014, pp1-11.

[29] S. Kalaga, P.Yenumula "Design of Electrical Transmission Lines, Structures and Foundations", Taylor \& Francis Group, London, UK Volume 1, 2017.

[30] A. Keyhani, M. N. Marwali, Min Dai, "Integration of green and renewable energy in electric power systems", Book, edition Wiley, chap.2, 2010. 